\title{
Article \\ The Effect of Under-Drilling and Osseodensification Drilling on Low-Density Bone: A Comparative Ex Vivo Study
}

\author{
Dong-Jun Seo ${ }^{1}{ }^{(}$, Seong-Yong Moon $\left.{ }^{1}{ }^{(}\right)$, Jae-Seek You ${ }^{1}$, Won-Pyo Lee ${ }^{2}\left(\mathbb{D}\right.$ and Ji-Su Oh ${ }^{1, *(1)}$ \\ 1 Department of Oral and Maxillofacial Surgery, School of Dentistry, Chosun University, Gwangju 61452, Korea; \\ seo415@naver.com (D.-J.S.); msygood@chosun.ac.kr (S.-Y.M.); applit375@chosun.ac.kr (J.-S.Y.) \\ 2 Department of Periodontology, School of Dentistry, Chosun University, Gwangju 61452, Korea; \\ wplee8@chosun.ac.kr \\ * Correspondence: jsoh@chosun.ac.kr; Tel.: +82-62-220-3813
}

check for updates

Citation: Seo, D.-J.; Moon, S.-Y.; You, J.-S.; Lee, W.-P.; Oh, J.-S. The Effect of Under-Drilling and Osseodensification Drilling on Low-Density Bone: A Comparative Ex Vivo Study. Appl. Sci. 2022, 12, 1163. https://doi.org/10.3390/ app12031163

Academic Editors: Gabriele Cervino, Alberto Bianchi and Pietro Felice

Received: 8 January 2022

Accepted: 21 January 2022

Published: 23 January 2022

Publisher's Note: MDPI stays neutral with regard to jurisdictional claims in published maps and institutional affiliations.

Copyright: (C) 2022 by the authors. Licensee MDPI, Basel, Switzerland. This article is an open access article distributed under the terms and conditions of the Creative Commons Attribution (CC BY) license (https:// creativecommons.org/licenses/by/ $4.0 /)$.
Featured Application: Osseodensification technique in the counter-clockwise direction increased the implant primary stability as well as the bone density around the implant holes on low-density bone.

\begin{abstract}
The aim of this study is to identify a method that can maximize implant primary stability (IPS) and bone density under the controlled drilling conditions of the same diameter and length in low-density bones through an ex vivo study. A total of 87 dental implants were placed with standard drilling, under-drilling, and osseodensification drilling in 13 fresh porcine sternums. The Periotest value and the implant stability quotient were measured to evaluate the primary stability. The difference in the Hounsfield unit (HU) between the hole and peripheral bone up to a distance of $1 \mathrm{~mm}$ was measured. Osseodensification and under-drilling technique increased the IPS, compared with conventional drilling technique with statistical significance under the drilling conditions of the same diameter and length. Osseodensification technique with the counter-clockwise direction had higher HU gaps than the standard drilling and osseodensification technique with clockwise direction. Due to the effect of bone densification, the gap of HU was increased by a minimum of $43 \mathrm{HU}$ and a maximum of $180 \mathrm{HU}$. Within the limitations of this ex vivo study, it was found that the osseodensification technique with counter-clockwise direction is effective to increase IPS and bone mineral density in low-density bone.
\end{abstract}

Keywords: biomechanics; bone density; dental implants; osseodensification; osseointegration

\section{Introduction}

Osseointegration, a prerequisite for successful implant loading, signifies a direct functional and structural union between the titanium surface and bone [1]. Osseointegration has been evaluated as the most important predictor of long-term implant success. According to Albrektsson et al. [2], six major factors-implant design, implant surface, implant material, surgical factors such as implant primary stability (IPS), biomechanical factors such as loading conditions, and patient-related factors, including bone density, quality, and volume-play key roles in osseointegration and implant success [3-6].

Among these, IPS is a key factor because it is related to all other categories of osseointegration [7]. IPS is successfully obtained when the micromotion of the implant is less than $50 \mu \mathrm{m}$ to $150 \mu \mathrm{m}$. Micromotion above this level causes bone resorption and fibrous encapsulation around the implant, leading to implant failure rather than osseointegration $[8,9]$. IPS is achieved only by a mechanical connection between the implant and the bone. After that, a biological remodeling proceeds in approximately $1 \mathrm{~mm}$ of the peripheral bone around the implant. This process will reduce the mechanical bone-to-implant contact (BIC), loosen implant stability, and make the area susceptible to micromovement and fibrous 
integration. However, as the bone is formed, BIC increases again, which is the so-called implant secondary stability $[10,11]$.

IPS is considerably influenced by the quantity and quality of the bone bed [2,12]. In particular, bone quality is an important determinant in early fixture loss [13]. Based on previous studies' classification of bone quality by measuring Hounsfield unit (HU) values on computed tomography (CT), type IV bone with poor bone density has a higher implant failure rate than that of type I, II, and III [12-16]. This is because implants placed in bones with low density, such as the posterior maxilla, have low IPS, and it is potentially difficult to obtain high insertion torque $[13,17]$.

Trabecular bone has less influence on IPS than marginal cortical bone. Therefore, IPS is difficult to obtain in areas with thin cortical bones and low trabecular bone density, such as the posterior maxilla $[12,13]$. Conventional technique, an osteotomy preparation method for implant placement, is a subtractive process that cuts and extracts the bone from the implant bed. Burs of conventional technique also facilitate this removal and are manufactured with a special design (deep grooves) to store the removed bone chips between the drill flutes for potential reuse [18].

One of the most popular methods to increase IPS in low-density bones is the underdrilling technique. It was found that a $10 \%$ undersized preparation in low-density bone is sufficient to improve IPS, and there is no significant effect with an additional reduction $[19,20]$. Stepped osteotomy was introduced as a modification and proved to be more effective than the conventional technique [21]. According to Summers [22], osteotomes are widely used to increase bone density and aid implant stability. In 2017, Huwais introduced the method called the osseodensification technique to increase IPS [23].

Osseodensification drill, which is non-subtractive, contains a specially designed structure with many lands that have large negative rake angles. This serves as a non-cutting edge to increase bone density when expanding the osteotomy and allows the bone to be preserved. These burs are designed to have a tapered shank and a cutting chisel edge, allowing the osteotomy to be expanded and the diameter to be gradually increased as the burs enter deeper. They can be rotated clockwise (cutting direction) to drill bone or counter-clockwise (non-cutting direction) to smoothly compact bone [23].

Although many studies on osseodensification drilling have been reported [10,23-25], few studies have compared various drilling techniques, and in particular, there has been no study comparing under-drilling and osseodensification drilling under the controlled drilling conditions of the same diameter and length in low-density bones. The aim of this ex vivo study is to identify a method that can maximize IPS and bone density in low-density bones by objective evaluation using various drilling techniques (under-drilling technique and osseodensification technique).

\section{Materials and Methods}

\subsection{Bone Sample and Experimental Groups}

We prepared 13 pig sternums for 87 implant drillings. All bone samples included trabecular bones only to exclude the effect of cortical bone and were drilled with a distance between the holes at least $3 \mathrm{~mm}$. The experiment was conducted with the IPS test and bone density test. IPS test was divided into two groups: standard drilling (drilling up to the same size as the implant diameter) and under-drilling. Each group was further subdivided, based on the drilling technique, into three groups: conventional technique (CD), osseodensification technique (OD) in the clockwise direction (OD-C), and OD in the counter-clockwise direction (OD-CC). The sample size for the IPS test was 10 for each group $(n=10)$. The bone density test was divided into three groups: CD, OD-C, and OD-CC. Each group was further subdivided according to diameter for a three-step sequence with a difference of $1 \mathrm{~mm}$. The sample size for the bone density test was 3 for each group $(\mathrm{n}=3)$. 


\subsection{Implant Bed Preparation and Implant Installation}

The implant bed was prepared according to the manufacturer's recommendations. The drilling speed was 1400 RPM, and insertion torque was $50 \mathrm{Ncm}$ for CD and OD-C groups, 800 RPM, and 30 Ncm for the OD-CC group. For the IPS test, 60 Osstem tapered implants (TSIII SA pre-mounted, OSSTEM IMPLANT Co. Ltd., Seoul, Korea), with $4.5 \mathrm{~mm}$ diameter and $10 \mathrm{~mm}$ length were installed, with the engine set at 50 RPM and maximum $50 \mathrm{Ncm}$ torque.

\subsection{Evaluation of Implant Primary Stability}

Depending on the manufacturer, the actual diameter, length, and taper of the burs are different. Since these conditions affect the IPS after implant insertion, the actual diameter, length, and taper of the burs used were adjusted within the $0.2 \mathrm{~mm}$ error range. Osstem tapered burs (TPD3C, OSSTEM IMPLANT Co. Ltd., Seoul, Korea), with a final $4.3 \mathrm{~mm}$ (standard drilling) or $3.8 \mathrm{~mm}$ (under-drilling) major diameter and $10 \mathrm{~mm}$ length, were used for CD, and Versah universal tapered burs (VT, Versah LLC, Jackson, MI, USA), with a final $4.3 \mathrm{~mm}$ (standard drilling) or $4.0 \mathrm{~mm}$ (under-drilling) major diameter and $10 \mathrm{~mm}$ length, were used for OD. IPS was evaluated using two methods: resonance frequency analysis (RFA) and Periotest. Immediately after the implant insertion, the Periotest value (PTV) was evaluated, using the Periotest device (Periotest ${ }^{\circledR}$ M, Medizintechnik Gulden e.K., Modautal, Germany), and the implant stability quotient (ISQ) was tested using the Osstell device (Osstell ${ }^{\circledR}$ ISQ, OSSTELL, Göteborg, Sweden), in each group of IPS test. PTV and ISQ were randomly measured twice per implant.

\subsection{Evaluation of Bone Density}

Drilling was carried out in a 3-step sequence, with a difference of $1 \mathrm{~mm}$ in diameter, according to the manufacturer's instructions. Osstem tapered burs (TPD3C, OSSTEM IMPLANT Co. Ltd., Seoul, Korea) with a final $3.8 \mathrm{~mm}, 4.8 \mathrm{~mm}$, and $5.8 \mathrm{~mm}$ major diameter and $10 \mathrm{~mm}$ length were used for CD of bone density test, and Versah universal tapered burs (VT, Versah LLC, Jackson, MI, USA) with a final $3.5 \mathrm{~mm}, 4.5 \mathrm{~mm}$, and $5.5 \mathrm{~mm}$ major diameter and $10 \mathrm{~mm}$ length were used for OD. The bone density of the implant bed was scanned using a micro-positron emission tomography/computed tomography (CT) scanner (Quantum GX, PerkinElmer Inc., Waltham, MA, USA). Image scanning conditions were as follows: $90 \mathrm{kV}$ voltage, $80 \mu \mathrm{A}$ current, $45 \mathrm{~mm}$ field of view (FOV), 4 min exposure time, and $90 \mu \mathrm{m}$ voxel size. Scanned images were obtained using Quantum Image Viewer software (Quantum GX SimpleViewer, PerkinElmer Inc., Waltham, MA, USA). BMD of the samples was measured using biomedical imaging analysis software (Analyze 12.0, AnalyzeDirect Inc., Stilwell, KS, USA). The total mean BMD value of the sternum including the cortical and trabecular bone was $131.57 \pm 10.14 \mathrm{mg} / \mathrm{cm}^{3}$ (Figure 1).
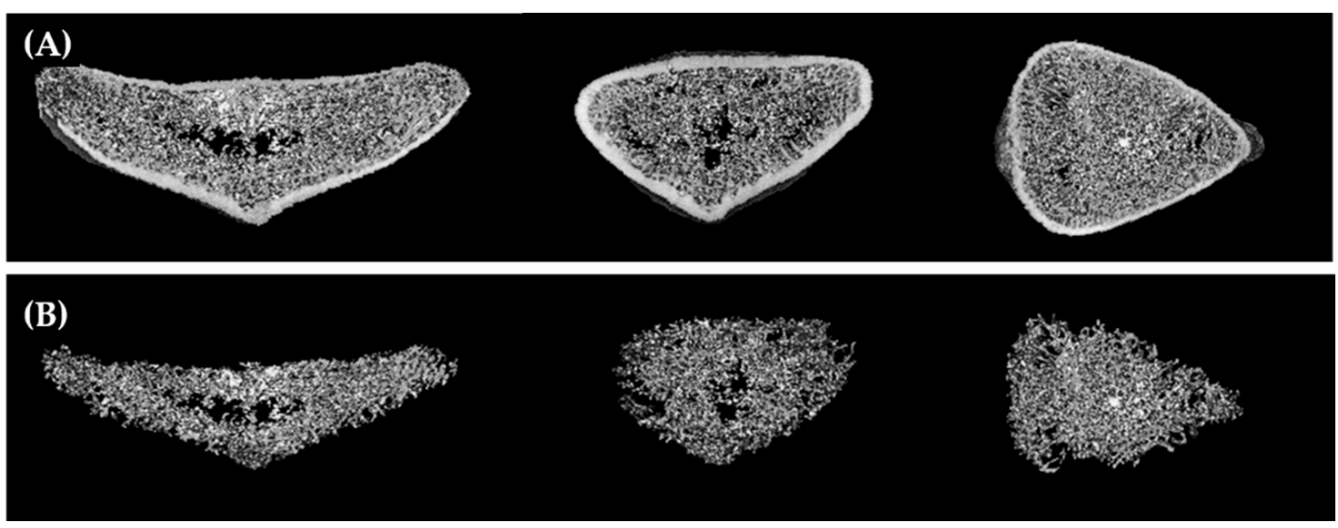

Figure 1. Micro-positron emission tomography/computed tomography images of the sternum: (A) total bone; (B) trabecular bone. 
The difference in HU between the implant hole and peripheral bone was measured in each group of bone density tests and subdivided into coronal ( $1 \mathrm{~mm}$ distance from the upper surface), middle (5 $\mathrm{mm}$ distance), and apical (9 $\mathrm{mm}$ distance) areas. The region of interest was identified as the surrounding bone to a distance of $1 \mathrm{~mm}$ from the surface of the hole, and it was measured 10 times per group (Figure 2).

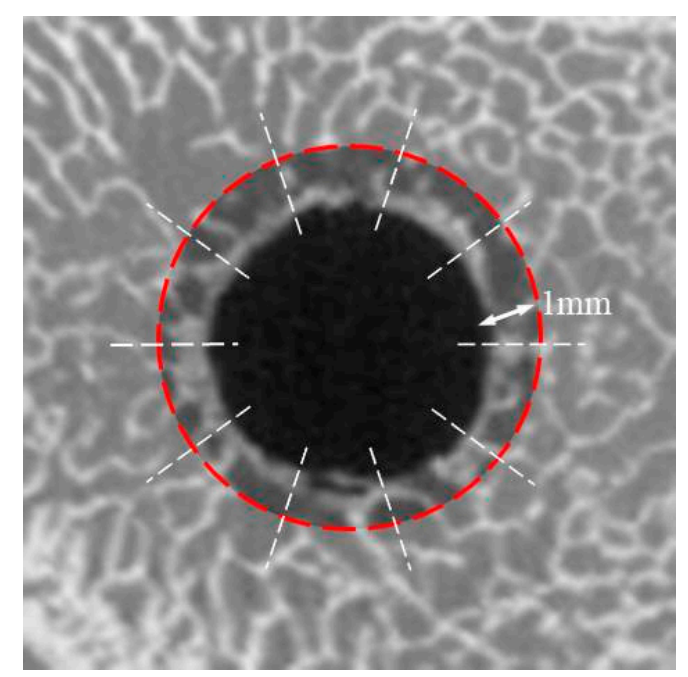

Figure 2. The region of interest to measure the difference in the Hounsfield unit of bone density test.

\subsection{Statistical Analysis}

ISQ values, PTVs, and HU gaps of the coronal area at each diameter step were statistically compared among groups using a non-parametric test, the Kruskal-Wallis test, and the Mann-Whitney test. Statistical comparison of HU values of the middle and apical areas at each diameter step was analyzed using a one-way analysis of variance with Tukey's post hoc test (ANOVA). Statistical analysis was performed using the SPSS software (SPSS 20.0, IBM Corp., Armonk, NY, USA). Statistical significance was set at $p<0.05$.

\section{Results}

\subsection{Implant Primary Stability}

Under-drilling with OD-CC (ISQ: $81.25 \pm 3.09$, PTV: $-7.67 \pm 0.47$ ) had the highest value of IPS with statistical significance $(p<0.05)$, and standard drilling with CD (ISQ: $66.35 \pm 2.11$, PTV: $-4.38 \pm 1.58)$ showed the lowest IPS among all groups. Under-drilling groups showed higher IPS than standard drilling groups, regardless of drilling techniques $(p<0.05)$.

The IPS values of the OD-CC group were the highest in the standard and under drilling groups. Under-drilling with CD (UD) (ISQ: $74.25 \pm 2.10$, PTV: $-6.23 \pm 0.87$ ) had higher IPS, compared with standard drilling with OD-CC (ISQ: $71.25 \pm 2.57$, PTV: $-6.10 \pm 0.87$ ), with statistical significance on ISQ $(p<0.05)$ but not on PTV (Tables 1 and 2$).$

Table 1. Implant stability quotient values in the experimental groups.

\begin{tabular}{cccc}
\hline & Group & ISQ Value & Comparison between Groups * \\
\hline A & Standard drilling with CD & $66.35 \pm 2.11$ & C, D \\
B & Standard drilling with OD-C & $67.85 \pm 3.59$ & C, E \\
C & Standard drilling with OD-CC & $71.25 \pm 2.57$ & A, B, D, F \\
D & Under-drilling with CD & $74.25 \pm 2.10$ & A, C, F \\
E & Under-drilling with OD-C & $78.30 \pm 3.83$ & B, F \\
F & Under-drilling with OD-CC & $81.25 \pm 3.09$ & C, D, E \\
\hline
\end{tabular}

ISQ, implant stability quotient; CD, conventional technique; OD-C, osseodensification technique in the clockwise direction; OD-CC, osseodensification technique in the counter-clockwise direction. ${ }^{*}$ Statistically significant difference ( $p<0.05$; Kruskal-Wallis test). 
Table 2. Periotest values in the experimental groups.

\begin{tabular}{cccc}
\hline & Group & ISQ Value & Comparison between Groups * \\
\hline A & Standard drilling with CD & $-4.38 \pm 1.58$ & C, D \\
B & Standard drilling with OD-C & $-5.49 \pm 1.51$ & E \\
C & Standard drilling with OD-CC & $-6.10 \pm 0.87$ & A, F \\
D & Under-drilling with CD & $-6.23 \pm 0.87$ & A, F \\
E & Under-drilling with OD-C & $-7.02 \pm 0.98$ & B, F \\
F & Under-drilling with OD-CC & $-7.67 \pm 0.47$ & C, D, E \\
\hline
\end{tabular}

PTV, Periotest value; CD, conventional technique; OD-C, osseodensification technique in the clockwise direction OD-CC, osseodensification technique in the counter-clockwise direction. * Statistically significant difference $(p<0.05 ;$ Kruskal-Wallis test).

\subsection{Bone Density}

Regardless of the difference in diameters, OD-CC groups had higher HU gaps than the CD and OD-C groups $(p<0.05)$, in all areas (coronal, middle, and apical area). There was no statistical difference in diameters between CD and OD-C groups. In OD-CC, the larger the drilling diameter was, the higher was the HU gap, in all areas, indicating that it was the highest for $5.5 \mathrm{~mm}$ diameter. However, this was significant only between $3.5 \mathrm{~mm}$ and $5.5 \mathrm{~mm}(p<0.05)$ (Table 3).

Table 3. Hounsfield unit gaps in groups.

\begin{tabular}{ccccc}
\hline & Drilling Diameter & Coronal Area & Middle Area & Apical Area \\
\hline CD & $3.8 \mathrm{~mm}$ & $587.50 \pm 65.24$ & $572.50 \pm 84.17$ & $583.33 \pm 83.39$ \\
& $4.8 \mathrm{~mm}$ & $604.17 \pm 71.94$ & $610.83 \pm 61.48$ & $615.00 \pm 87.74$ \\
& $5.8 \mathrm{~mm}$ & $615.84 \pm 61.41$ & $595.00 \pm 87.94$ & $582.50 \pm 81.25$ \\
\hline OD-C & $3.5 \mathrm{~mm}$ & $602.50 \pm 69.28$ & $604.17 \pm 61.97$ & $606.67 \pm 63.29$ \\
& $4.5 \mathrm{~mm}$ & $588.33 \pm 64.57$ & $611.67 \pm 72.14$ & $611.67 \pm 75.64$ \\
& $5.5 \mathrm{~mm}$ & $605.83 \pm 82.44$ & $603.33 \pm 69.09$ & $596.67 \pm 86.29$ \\
\hline OD-CC & $3.5 \mathrm{~mm}$ & $648.33 \pm 76.26$ & $647.50 \pm 59.94$ & $704.17 \pm 52.56$ \\
& $4.5 \mathrm{~mm}$ & $672.50 \pm 76.38$ & $690.00 \pm 75.89$ & $745.83 \pm 74.30$ \\
& $5.5 \mathrm{~mm}$ & $685.00 \pm 59.67$ & $714.17 \pm 73.01$ & $776.67 \pm 79.31$ \\
\hline
\end{tabular}

$\overline{\mathrm{CD}}$, conventional technique; OD-C, osseodensification technique in the clockwise direction; OD-CC, osseodensification technique in the counter-clockwise direction.

Regardless of diameter, apical values were significantly highest values in all OD-CC groups $(p<0.05)$. There were no significant differences between the coronal and middle areas. There were no statistical differences in any area between the CD and OD-C groups. Comparing OD-C and OD-CC groups, there was a difference of a minimum of $43 \mathrm{HU}$ in the middle area with a $3.5 \mathrm{~mm}$ diameter, and a maximum 180 of $\mathrm{HU}$ in the apical area with $5.5 \mathrm{~mm}$ diameter (Figures 3-6). 

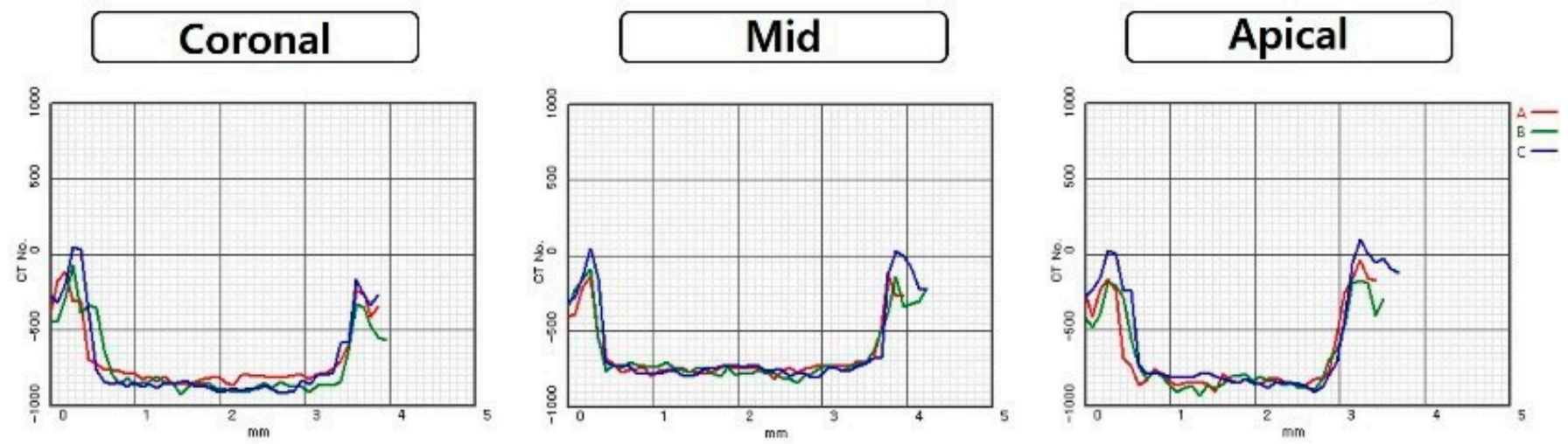

Figure 3. Comparison of Hounsfield unit gaps according to area at $3.8 \mathrm{~mm}$ diameter of conventional technique and $3.5 \mathrm{~mm}$ diameter of osseodensification technique: (A) conventional technique; (B) osseodensification technique in the clockwise direction; (C) osseodensification technique in the counter-clockwise direction.
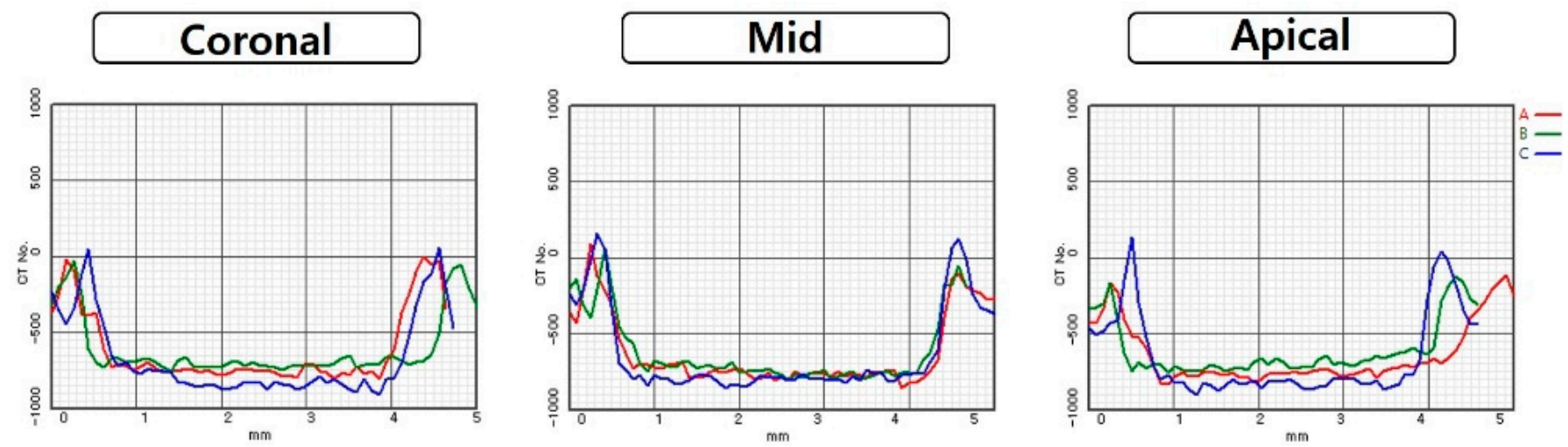

Figure 4. Comparison of Hounsfield unit gaps according to area at $4.8 \mathrm{~mm}$ diameter of conventional technique and $4.5 \mathrm{~mm}$ diameter of osseodensification technique: (A) conventional technique; (B) osseodensification technique in the clockwise direction; (C) osseodensification technique in the counter-clockwise direction.
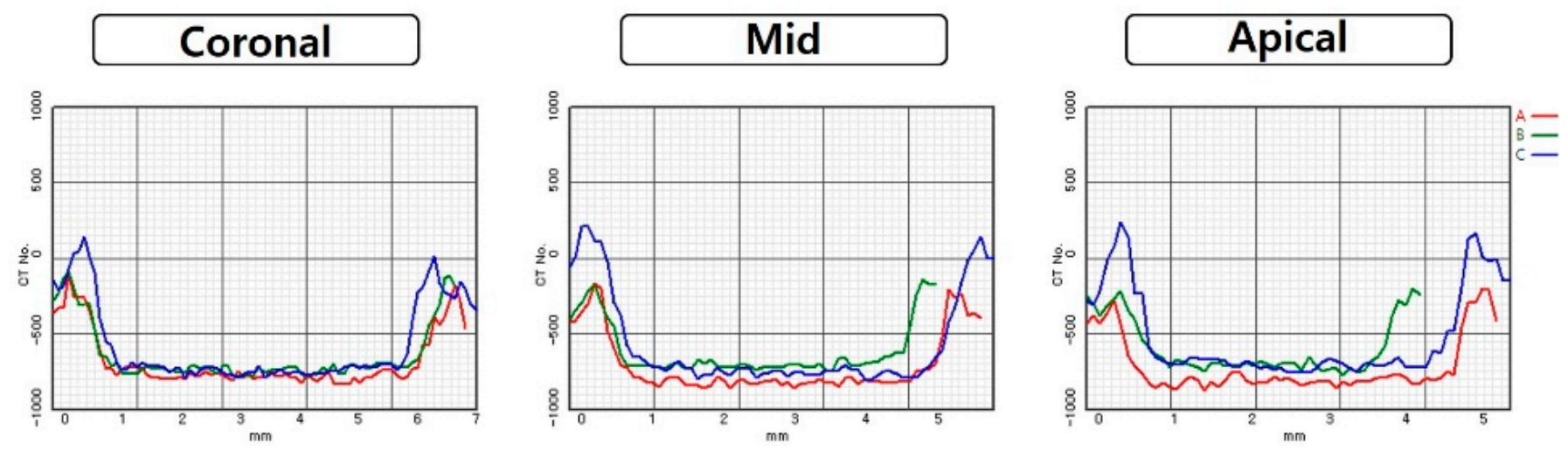

Figure 5. Comparison of Hounsfield unit gaps according to area at $5.8 \mathrm{~mm}$ diameter of conventional technique and $5.5 \mathrm{~mm}$ diameter of osseodensification technique: (A) conventional technique; (B) osseodensification technique in the clockwise direction; (C) osseodensification technique in the counter-clockwise direction. 

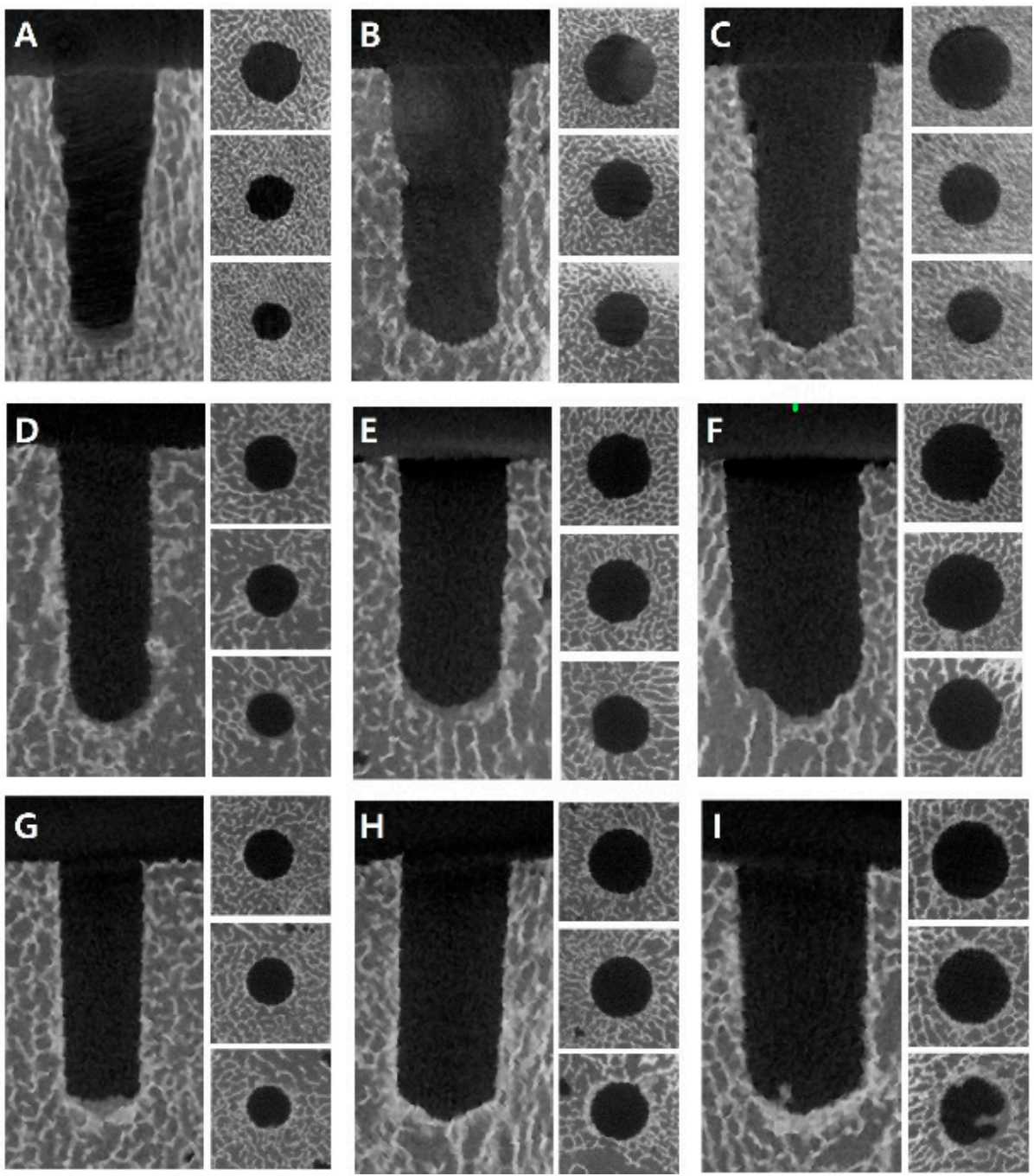

Figure 6. Comparison of bone density around the drilling holes on micro-positron emission tomography/computed tomography images according to diameters and techniques: (A) conventional technique (CD) with $3.8 \mathrm{~mm}$ drilling; (B) CD with $4.8 \mathrm{~mm}$ drilling; (C) CD with $5.8 \mathrm{~mm}$ drilling; (D) osseodensification technique in the clockwise direction (OD-C) with $3.5 \mathrm{~mm}$ drilling; (E) OD-C with $4.5 \mathrm{~mm}$ drilling; (F) OD-C with $5.5 \mathrm{~mm}$ drilling; (G) osseodensification technique in the counterclockwise direction (OD-CC) with $3.5 \mathrm{~mm}$ drilling; (H) OD-CC with $4.5 \mathrm{~mm}$ drilling; (I) OD-CC with $5.5 \mathrm{~mm}$ drilling.

\section{Discussion}

According to previous studies [26-28], the distal tibia and radius had a value of $169 \pm 34 \mathrm{mg} / \mathrm{cm}^{3}$ and $160 \pm 33 \mathrm{mg} / \mathrm{cm}^{3}$. The measurements of the thoracic spine (Th10) and lumbar spine (L4) showed a value of $90.4 \pm 28.9 \mathrm{mg} / \mathrm{cm}^{3}$ and $80.8 \pm 32.4 \mathrm{mg} / \mathrm{cm}^{3}$. A value of $295.2 \pm 93.6 \mathrm{mg} / \mathrm{cm}^{3}$ and $293.4 \pm 112.1 \mathrm{mg} / \mathrm{cm}^{3}$ were observed in the right and left maxillary posterior regions. The sternums $\left(131.57 \pm 10.14 \mathrm{mg} / \mathrm{cm}^{3}\right)$ used in this study corresponded to the low-density bone. Oliveira et al. [13] and Lindh et al. [14] analyzed $\mathrm{CT}$ to evaluate the mandibular and maxillary bones and measured the density (HU) of only trabecular bone without cortical bone. They explained that the values of bone type IV were less than $+200 \mathrm{HU}$, those of types II and III were between $+200 \mathrm{HU}$ and $+400 \mathrm{HU}$, and those of type I were larger than $+400 \mathrm{HU}$. The increase in the HU gap indicated an increase in bone condensation in the peripheral and apical areas, which led to an improvement in BMD. The density of air was equal to $-1000 \mathrm{HU}$, water to 0 (zero) HU in our study. Although it is difficult to make an absolute comparison with the values of those studies, it 
can be explained that the bone density was increased because the gap values were increased. Due to the effect of the osseodensification technique, the gap of HU was increased by a minimum of $43 \mathrm{HU}$ and a maximum of $180 \mathrm{HU}$. These results show that the poor density bone such as type IV can be changed to densified bone such as type II or III.

Clinically, there are three methods to measure implant stability: insertion torque measurement, RFA, and Periotest. The IPS is directly correlated with the implant insertion torque. According to Norton [29], an implant insertion torque of $25 \mathrm{Ncm}$ is sufficient for clinically successful primary stability. However, in the case of immediately loaded implants, at least $32 \mathrm{Ncm}$ insertion torque is required and $45 \mathrm{Ncm}$ is needed in sites of low-density bone [30,31]. Moreover, a high insertion torque $(>50 \mathrm{Ncm})$ causes microfracture or bone necrosis of the peri-implant bone area in the early healing stages, which may weaken the primary stability and result in implant failure [32]. Implant torque can be measured using a digital torque wrench or implant motor, but it can only be measured at the time of implant insertion [3].

RFA and Periotest have been proposed to clinically evaluate implant stability because of their reproducibility [33]. Periotest is measured as the contact time of the device during repetitive percussion between the tapping rod and implant. RFA is measured electromagnetically as an ISQ unit, which means the resonance frequency is caused by the excitation of a small implant peg attached to the implant [34]. RFA and Periotest, which are widely used in clinical practice and have a positive correlation with insertion torque [35], were used in this study.

Huwais et al. [23] invented a denser bur, which can be rotated counter-clockwise (non-cutting direction) to smoothly compact bone, or clockwise (cutting direction) to drill bone. With the compaction of cancellous bone by viscoelastic and plastic deformation and autografting effect, the osseodensification technique preserves the bone volume [23]. The insertion torque of $25 \mathrm{Ncm}$ with standard drilling is increased to $49 \mathrm{Ncm}$ with the osseodensification technique [23]. The residual strains of viscoelasticity create compressive forces against the surface of implants, called the springback effect, which increases IPS and BIC [36]. In addition to high IPS, it was reported that osseodensification drilling exhibited higher secondary stability than subtractive drilling during the first 6 weeks without detrimental effect $[37,38]$.

The preparation of the osseodensification technique should start with a smaller diameter than the conventional technique because of the recovery of elastic strain. Owing to its special design and usage, a condensed autografted bone layer is created around the periphery and at the apex of the hole $[39,40]$.

If the hole of the osseodensified osteotomy remained empty, the hole diameter was decreased by $91 \%$. It is important to obtain a high IPS and BIC for osseointegration of implants [23]. When the osseodensification technique was used, the diameter of the osteotomy site became smaller, the boundary of the osteotomy site became more condensed in the scanning electron microscope and micro-CT images, and the rate of contact between the bone and implant surface became three times higher. The densification of the bone did not occur in the cortical bone, as it lacked elasticity. Similar results were obtained in this study. The gap of HU in the bone using the osseodensification technique in the counter-clockwise direction was greater than that using the conventional technique and osseodensification technique in the clockwise direction. This indicates that the osseodensification technique compacts the bone around the hole and increases bone density. This is probably because osseodensification burs deposit bones rather than subtract during counter-clockwise rotation.

Almutairi et al. evaluated the effect of the osseodensification technique on IPS and compared it with the conventional technique [24]. In total, 48 implants with a different tread design were inserted into the head of a cow femur using conventional and osseodensification techniques. The PTVs were measured to evaluate the IPS. There was no statistically significant difference in the PTV between conventional and osseodensification techniques. The PTV of the conventional technique was better than that of the osseodensification 
technique. This may be because the osseodensification technique is not useful in dense, compact bones such as Type I and II. It was shown that the osseodensification technique is ineffective and not essential when the quality and quantity of the bone bed are good. In this study, conducted in low-density bone, the osseodensification technique had a higher IPS than the conventional technique, regardless of the direction. In particular, the IPS of the osseodensification technique in the clockwise direction was higher than the conventional technique, even under the same conditions controlled. This means that the design of the osseodensification bur is more effective to increase IPS than the conventional bur.

Cáceres et al. investigated the effect of the osseodensification technique on ISQ, insertion torque, and removal torque in pig tibia bones [25]. A total of 100 osteotomies were performed, and the osseodensification technique was compared with the conventional technique. Insertion and removal torques were measured manually using an analog Torque Gauge. All osseodensification technique values were significantly higher than those of the conventional technique. It was concluded that the osseodensification technique increases the ISQ, insertion torque, and removal torque, which means a high IPS.

Experiments of this study were conducted in low-density bone. It was concluded that, in low-density bone, the osseodensification technique has a better effect, compared with the conventional technique, on ISQ and PTV, increasing IPS. In addition, the osseodensification technique creates an increase in BMD of low-density bone by condensing the bones around the implant, based on the increased value of HU, compared with conventional and underdrilling techniques. It was proved that the under-drilling technique has a better effect on IPS than the conventional technique, but there is no difference in BMD. Higher IPS and better BMD increase osseointegration and lead to implant success.

Although this study is noteworthy since it allows for an objective assessment of implant primary stability and bone density in controlled conditions in low-density bones, there are limitations in evaluating only primary stability through ex vivo study. Further long-term clinical studies are needed on how the deposited and condensed bone by the osseodensification technique affects secondary stability for implant success.

\section{Conclusions}

In this study, the implant primary stability and bone density were evaluated using various drilling techniques in low-density bones, and the conclusions are as follows: (1) Osseodensification and under-drilling technique increased the implant primary stability, compared with conventional drilling technique; (2) the conventional technique and osseodensification technique in the clockwise direction did not deposit bone around the implant holes; (3) osseodensification technique in the counter-clockwise direction increased the implant primary stability, as well as the bone density around the implant holes.

Author Contributions: Conceptualization, J.-S.O. and D.-J.S.; methodology, D.-J.S.; software, D.-J.S.; validation, J.-S.O. and D.-J.S.; formal analysis, D.-J.S. and W.-P.L.; investigation, D.-J.S.; resources, D.-J.S.; data curation, D.-J.S. and S.-Y.M.; writing—original draft preparation, D.-J.S.; writing-review and editing, D.-J.S., S.-Y.M., J.-S.Y., W.-P.L. and J.-S.O.; visualization, D.-J.S. and J.-S.Y.; supervision, S.-Y.M., J.-S.Y., W.-P.L. and J.-S.O.; project administration, J.-S.O. All authors have read and agreed to the published version of the manuscript.

Funding: This research received no external funding.

Institutional Review Board Statement: Not applicable.

Informed Consent Statement: Not applicable.

Data Availability Statement: The datasets generated or analyzed during the current study are available from the corresponding author on reasonable request.

Acknowledgments: This study was supported by a research fund from Chosun University Dental Hospital, 2020.

Conflicts of Interest: The authors declare no conflict of interest. 


\section{References}

1. Brånemark, P.I. Osseointegration and its experimental background. J. Prosthet. Dent. 1983, 50, 399-410. [CrossRef]

2. Albrektsson, T.; Brånemark, P.I.; Hansson, H.A.; Lindström, J. Osseointegrated titanium implants: Requirements for ensuring a long-lasting, direct bone-to-implant anchorage in man. Acta Orthop. Scand. 1981, 52, 155-170. [CrossRef] [PubMed]

3. Trisi, P.; Perfetti, G.; Baldoni, E.; Berardi, D.; Colagiovanni, M.; Scogna, G. Implant micromotion is related to peak insertion torque and bone density. Clin. Oral Implants Res. 2009, 20,467-471. [CrossRef]

4. Brunski, J.B. In vivo bone response to biomechanical loading at the bone/dental-implant interface. Adv. Dent. Res. 1999, 13, 99-119. [CrossRef] [PubMed]

5. Stanford, C.M.; Brand, R.A. Toward an understanding of implant occlusion and strain adaptive bone modeling and remodeling. J. Prosthet. Dent. 1999, 81, 553-561. [CrossRef]

6. Fugazzotto, P.A.; Wheeler, S.L.; Lindsay, J.A. Success and failure rates of cylinder implants in type IV bone. J. Periodontol. 1993, 64, 1085-1087. [CrossRef] [PubMed]

7. Lioubavina-Hack, N.; Lang, N.P.; Karring, T. Significance of primary stability for osseointegration of dental implants. Clin. Oral Implants Res. 2006, 17, 244-250. [CrossRef] [PubMed]

8. Duyck, J.; Vandamme, K.; Geris, L.; van Oosterwyck, H.; De Cooman, M.; Vandersloten, J.; Puers, R.; Naert, I. The influence of micro-motion on the tissue differentiation around immediately loaded cylindrical turned titanium implants. Arch. Oral Biol. 2006, 51, 1-9. [CrossRef] [PubMed]

9. Soballe, K.; Brockstedt-Rasmussen, H.; Hansen, E.S.; Bunger, C. Hydroxyapatite coating modifies implant membrane formation. Controlled micromotion studied in dogs. Acta Orthop. Scand. 1992, 63, 128-140. [CrossRef] [PubMed]

10. Podaropoulos, L. Increasing the stability of dental implants: The concept of osseodensification. Balk. J. Dent. Med. 2017, 21, 133-140. [CrossRef]

11. Raghavendra, S.; Wood, M.C.; Taylor, T.D. Early wound healing around endosseous implants: A review of the literature. Int. J. Oral Maxillofac. Implants 2005, 20, 425-431. [PubMed]

12. Norton, M.R.; Gamble, C. Bone classification: An objective scale of bone density using the computerized tomography scan. Clin. Oral Implants Res. 2001, 12, 79-84. [CrossRef]

13. Jaffin, R.A.; Berman, C.L. The excessive loss of Branemark fixtures in type IV bone: A 5-year analysis. J. Periodontol. 1991, 62, 2-4. [CrossRef] [PubMed]

14. De Oliveira, R.C.G.; Leles, C.R.; Normanha, L.M.; Lindh, C.; Ribeiro-Rotta, R.F. Assessments of trabecular bone density at implant sites on CT images. Oral Surg. Oral Med. Oral Pathol. Oral Radiol. Endodontol. 2008, 105, 231-238. [CrossRef] [PubMed]

15. Lindh, C.; Obrant, K.; Petersson, A. Maxillary bone mineral density and its relationship to the bone mineral density of the lumbar spine and hip. Oral Surg. Oral Med. Oral Pathol. Oral Radiol. Endodontol. 2004, 98, 102-109. [CrossRef]

16. Turkyilmaz, I.; Tözüm, T.; Tumer, C. Bone density assessments of oral implant sites using computerized tomography. J. Oral Rehabil. 2007, 34, 267-272. [CrossRef]

17. Isoda, K.; Ayukawa, Y.; Tsukiyama, Y.; Sogo, M.; Matsushita, Y.; Koyano, K. Relationship between the bone density estimated by cone-beam computed tomography and the primary stability of dental implants. Clin. Oral Implants Res. 2012, 23, 832-836. [CrossRef]

18. Jackson, C.; Ghosh, S.; Johnson, W. On the evolution of drill-bit shapes. J. Mech. Work. Technol. 1989, 18, 231-267. [CrossRef]

19. Degidi, M.; Daprile, G.; Piattelli, A. Influence of underpreparation on primary stability of implants inserted in poor quality bone sites: An in vitro study. J. Oral Maxillofac. Surg. 2015, 73, 1084-1088. [CrossRef]

20. Alghamdi, H.; Anand, P.S.; Anil, S. Undersized implant site preparation to enhance primary implant stability in poor bone density: A prospective clinical study. J. Oral Maxillofac. Surg. 2011, 69, e506-e512. [CrossRef]

21. Boustany, C.M.; Reed, H.; Cunningham, G.; Richards, M.; Kanawati, A. Effect of a modified stepped osteotomy on the primary stability of dental implants in low-density bone: A cadaver study. Int. J. Oral Maxillofac. Implants 2015, 30, 48-55. [CrossRef] [PubMed]

22. Summers, R.B. A new concept in maxillary implant surgery: The osteotome technique. Compendium 1994, 15, 154-156. Available online: https:/ / pubmed.ncbi.nlm.nih.gov / 8055503 (accessed on 19 July 2021).

23. Huwais, S.; Meyer, E.G. A novel osseous densification approach in implant osteotomy preparation to increase biomechanical primary stability, bone mineral density, and bone-to-implant contact. Int. J. Oral Maxillofac. Implants 2017, 32, 27-36. [CrossRef]

24. Almutairi, A.S.; Walid, M.A.; Alkhodary, M.A. The effect of osseodensification and different thread designs on the dental implant primary stability. F1000Research 2018, 7, 1898. [CrossRef] [PubMed]

25. Cáceres, F.; Troncoso, C.; Silva, R.; Pinto, N. Effects of osseodensification protocol on insertion, removal torques, and resonance frequency analysis of BioHorizons ${ }^{\circledR}$ conical implants. An ex vivo study. J. Oral Biol. Craniofacial Res. 2020, 10, 625-628. [CrossRef] [PubMed]

26. Boutroy, S.; Bouxsein, M.L.; Munoz, F.; Delmas, P.D. In vivo assessment of trabecular bone microarchitecture by high-resolution peripheral quantitative computed tomography. J. Clin. Endocrinol. Metab. 2005, 90, 6508-6515. [CrossRef]

27. Link, T.M.; Bauer, J.; Kollstedt, A.; Stumpf, I.; Hudelmaier, M. Trabecular bone structure of the distal radius, the calcaneus, and the spine: Which site predicts fracture status of the spine best? Investig. Radiol. 2004, 39, 487-497. [CrossRef]

28. Montangero, V.E.; Capiglioni, R.; Roldán, E.J. Mandible and maxilla bone mineral density and threshold analysis studies by pQCT in two edentulous women receiving pamidronate. Cranio 2003, 21, 110-115. [CrossRef] 
29. Norton, M.R. The influence of insertion torque on the survival of immediately placed and restored single-tooth implants. Int. J. Oral Maxillofac. Implants 2011, 26, 1333-1343. [PubMed]

30. Ottoni, J.M.P.; Oliveira, Z.F.L.; Mansini, R.; Cabral, A.M. Correlation between placement torque and survival of single-tooth implants. Int. J. Oral Maxillofac. Implants 2005, 20, 769-776.

31. Trisi, P.; Berardi, D.; Paolantonio, M.; Spoto, G.; D'Addona, A.; Perfetti, G. Primary stability, insertion torque, and bone density of conical implants with internal hexagon: Is there a relationship? J. Craniofacial Surg. 2013, 24, 841-844. [CrossRef] [PubMed]

32. Barone, A.; Alfonsi, F.; Derchi, G.; Tonelli, P.; Toti, P.; Marchionni, S.; Covani, U. The effect of insertion torque on the clinical outcome of single implants: A randomized clinical trial. Clin. Implants Dent. Relat. Res. 2016, 18, 588-600. [CrossRef] [PubMed]

33. Aparicio, C.; Lang, N.P.; Rangert, B. Validity and clinical significance of biomechanical testing of implant/bone interface. Clin. Oral Implants Res. 2006, 17, 2-7. [CrossRef] [PubMed]

34. Sennerby, L.; Meredith, N. Resonance frequency analysis: Measuring implant stability and osseointegration. Compend. Contin. Educ. Dent. 1998, 19, 493-498. [PubMed]

35. Gallardo, S.; Ibanez, M.C.; Ibanez, J.C. Correlation between ISQ and insertion torque values using double acid-etched implants. J. Osseointegr. 2016, 8, 29-36. [CrossRef]

36. Kold, S.; Bechtold, J.; Ding, M.; Chareancholvanich, K.; Rahbek, O.; Søballe, K. Compacted cancellous bone has a spring-back effect. Acta Orthop. Scand. 2003, 74, 591-595. [CrossRef]

37. Alifarag, A.M.; Lopez, C.D.; Neiva, R.F.; Tovar, N.; Witek, L.; Coelho, P.G. Atemporal osseointegration: Early biomechanical stability through osseodensification. J. Orthop. Res. 2018, 36, 2516-2523. [CrossRef]

38. Bergamo, E.T.P.; Zahoui, A.; Barrera, R.B.; Huwais, S.; Coelho, P.G.; Karateew, E.D.; Bonfante, E.A. Osseodensification effect on implants primary and secondary stability: Multicenter controlled clinical trial. Clin. Implants Dent. Relat. Res. 2021, 23, 317-328. [CrossRef] [PubMed]

39. Trisi, P.; Berardini, M.; Falco, A.; Vulpiani, M.P. New osseodensification implant site preparation method to increase bone density in low-density bone: In vivo evaluation in sheep. Implants Dent. 2016, 25, 24-31. [CrossRef] [PubMed]

40. Padhye, N.M.; Padhye, A.M.; Bhatavadekar, N.B. Osseodensification-A systematic review and qualitative analysis of published literature. J. Oral Biol. Craniofacial Res. 2020, 10, 375-380. [CrossRef] 